\title{
DERECHO A LA VIDA Y PERSONA HUMANA
}

\author{
Juan de Dios Vial Correa \\ Rector de la Pontificia Universidad Católica de Chile. \\ Presidente de la Academia Pontificia para la Vida.
}

Agradezco muy cordialmente la invitación que me ha hecho la Escuela de Derecho a tomar parte en este ciclo de conferencias. Me alegro de la oportunidad de adherir en esta forma a los 40 años de la Universidad Católica del Norte, ya que me fue imposible hacerlo en persona con ocasión de la celebración en Antofagasta.

Creo que el tema que Uds. han escogido es fundamental para la sociedad humana, y que debemos abordarlo seriamente y en forma reiterada hasta llegar a compenetrarnos de todos sus aspectos. El título de la exposición que voy a hacer "DERECHO A LA VIDA Y PERSONA HUMANA", toca una aspecto que trataré de desarrollar lo más adecuadamente que me sea posible.

Un derecho mío es generalmente correlativo a un deber que alguien tiene respecto de mí. Así mi derecho a poseer, a tener algo, mi derecho de propiedad, es correlativo al deber que tienen todos de no arrebatármelo. Mi derecho a la vida es correlativo del deber que tienen todos los otros de no dañarme, de no quitarme la vida. El sujeto de esos deberes correlativos es siempre una persona que está obligada a respetar mis derechos. Puede, por supuesto, tratarse de un colectivo de personas, pero en ningún caso de una circunstancia natural. Así una industria contaminante puede ofender mi derecho a un medio ambiente sano, pero no lo ofende un terremoto. Otro hombre, o un grupo de hombres, pueden ofender mi derecho a la vida, pero no podría nunca decir que una enfermedad natural que me la quita está lesionando ese derecho. Así, los deberes que otros tienen respecto de mí pueden orientarmente para darme una idea de lo que piensan que yo soy.

Espontáneamente yo pienso que los otros tienen el deber de respetarme. ¿Qué quiero decir con esto?. Más o menos lo siguiente. Que ellos deben considerarme como un individuo que no está disponible para ellos, para ser usado para sus propios fines. Es lo que se quiere decir cuando se dice que la persona humana no puede nunca ser un medio para otras cosas, sino que tiene una dimensión fundamental según la cual ella es en si misma un fin. Eso puede serme oscuro a ratos, cuando pienso, por ejemplo, en la condición de una persona a quien yo le pago un salario para que haga un trabajo para mí, pero en principio parece claro que nadie tiene el derecho de usarme como un instrumento, todos tienen, al contrario, el deber de respetarme a mí como quien tiene un fin en si mismo.

El respeto que yo considero un deber de los otros hacia mí, incluye la aceptación de que yo poseo algunas características que no me pueden ser desconocidas, sin atentar contra el mismo respeto. Así, no podría aceptar que se me considerara como un sujeto desprovisto de libertad para conocer y para elegir. El reconocimiento de esa mi libertad 
forma parte integral del respeto que se me debe, su desconocimiento me parecería abusivo. En la misma línea pienso que se me debe reconocer una intimidad, a la cual nadie tiene acceso si yo mismo libremente no se lo franqueo. El respeto incluye más todavía. Debe reconocerse que soy gestor o sujeto de un destino o proyecto propio que me pertenece a mí solo, y no a mi especie o a mi sociedad. Al decir que soy un hombre, o una mujer, estoy diciendo que soy éste hombre en particular, que es irrepetible, peculiar, y estoy diciendo que en este hecho de ser éste y no algún otro cualquiera, radica algo fundamental de mi condición humana.

Pero no creo que me baste con exigir que se me respete. De hecho yo pienso que los otros tienen el deber de acogerme. Esto significa que mis aspiraciones y deseos, en cuanto ellos no dañen, perjudiquen o pongan a peligro a los demás hombres, deben ser acogidas por ellos. Creo que si otro hombre piensa que mis aspiraciones o proyectos le son dañosos, él tiene como mínima muestra de acogida la obligación de pensar en el motivo o razón de su rechazo. Pero yo encontraría profundamente injusto que alguien le negara siquiera esa mínima acogida a aspiraciones que me fueran importantes, aunque dicha acogida no significara para nada aprobar o aceptar mis aspiraciones. Pero hay un mínimo de buena voluntad que me es debido. Así, por ejemplo, si quiero saber, si quiero informarme sin dañar a nadie, pienso espontáneamente que el que puede educarme tiene en principio el deber de hacerlo, a no ser que pueda mostrarse asimismo o bien mostrarme a mí una buena razón para dejarme en la ignorancia.

En la misma línea, estimo que el otro tiene el deber de ayudarme o promoverme. Sólo si esa ayuda le causara al otro un daño desproporcionado, encontraría yo legítimo que me la negara. Me parecería espontáneamente que el que me negara sin riesgo para él la mano para evitar que me caiga en la calle, me está haciendo una injusticia. En cada coyuntura de la vida yo estoy siempre identificando estos bienes que me son importantes, que los otros me pueden dar o reconocer, y es mi espontánea condición que esos bienes nadie puede negármelos sin tener una razón proporcionada para hacerlo. Pero la condición humana es de tal naturaleza que si yo admito que los otros tienen el deber de respetarme, de acogerme, de promoverme, eso significa que cada hombre tiene derecho a ser respetado, acogido, promovido y, significa, por ende, que yo tengo el deber, el mismo deber que otros para mi, de respetar, acoger y promover a cada hombre. Para que mi derecho sea verdaderamente tal debo aceptar que él es universal. Cuando de derechos básicos se trata no podemos permitir que ello sea cuestión de gustos. A ese nivel, mi bien es el bien del otro, el bien del otro es el mío, y la negación que se le hace a alguien de uno de los bienes fundamentales rompe todo el tejido de la convivencia humana. Esta intuición es muy antigua en la humanidad. Así, por ejemplo, en la Biblia se registra el daño permanente causado por el homicidio de Caín. Lamec, su descendiente inmediato, se jacta y se enorgullece por crímenes mucho peores que el asesinato de Abel. Un solo gran crimen, gran delito, corrompe de hecho a toda la vida social.

Lo esencial entonces es que todos tienen el deber de respetar, acoger y promover a todos. Prefiero ponerlo así, como un deber más que como el derecho a ser respetado, acogido, o promovido, porque de esta manera hago resaltar algo que es también obvio. Esta relación humana no se da sin trabajo, sin esfuerzo, sin una libre accesis, es un camino de subida, una actividad y esa es una diferencia fundamental entre esta consideración de relación humana fundamental y, por ejemplo, las leyes positivas. Es evidente que no hay ninguna ley positiva que pueda ordenarme hacer algunas cosas, 
como, por ejemplo, consolar a otro, y, sin embargo, yo estoy obligado a consolar a otro hasta el límite, por lo menos, de mis normales posibilidades. Esto significa dos cosas que son estrechamente relacionadas entre sí, y que pueden ser miradas, la una, como una consideración individual y, la otra, como una consideración social de lo que he expresado hasta aquí.

En lo individual todo hombre debe ser tratado respetando o promoviendo su valor de persona. En lo social, está dicho por Juan Pablo II en la Encíclica "Evangelium Vitae". Lo cito: "El Dios de la Alianza ha confiado la vida de cada hombre a otro hombre hermano suyo, según la reciprocidad del dar y recibir, del don de si mismo y la acogida del otro" (en el número 76 de la Encíclica). Como se comprende, no estoy aquí invocando la Encíclica por su autoridad de documento de iglesia, sino por que ella nos recuerda muy acertadamente que la condición humana requiere para la vida social la existencia de una medida de acogida recíproca, sin esas condiciones no creo que podamos vivir, por lo menos, vivir en sociedad.

Ahora, esas condiciones apuntan a una realidad fundamental que es el reconocimiento de la persona humana y el valor de su dignidad, como fundamento de la sociedad humana. Quiero recalcar que como esto es básico, fundamental de la condición humana, a la misma conclusión podemos llegar por otros caminos. Por ejemplo, estamos acostumbrados, creo que todos nosotros, a pensar en la persona humana bajo la condición de individuo, a pensar primero en lo que soy y sólo secundariamente en mi relación con los otros, pero basta pensar un poco para darse cuenta de que esa es una perspectiva errada, irracional, incluso para pensar, para la actividad de pensar. Incluso cuando estoy solo en mi pieza yo uso el lenguaje y, por supuesto, el lenguaje no es nunca de uno solo, es un hecho social, y lo fundamental del lenguaje es que requiere de un interlocutor. Propiamente a las cosas no les hablo, les hablo a los otros y ellos me hablan a mí. Y el interlocutor que aparece así como un elemento determinante de mi propia vida, tiene una propiedad muy especial. Todos los objetos, los otros objetos así como los conceptos que me hago a partir de ellos, son en cierto modo de mi propiedad. Al menos en la imaginación puedo disponer de ellos y no tengo propiamente obligación alguna hacia ellos. Pero basta que haya un sólo otro, un solo interlocutor real o posible en el mundo para que eso cambie, porque frente a él tengo y no puedo ignorarlo, una responsabilidad.

Piense cada uno en su vecino. Mi relación primordial, fundante con él es de tipo ético, que es lo mismo que he estado señalando por otro camino. Todavía podría haber seguido el camino de una justificación rigurosa de la persona humana, a partir de consideraciones filosóficas que son clásicas en el pensamiento occidental, pero yo prefiero seguir este camino que no es el de una demostración o defensa filosófica del concepto de persona, sino el develamiento, el mostramiento, el mostrar un entramado ético que no se entiende sin ella, sin la persona y sobre el cual, el entramado ético, descansa la sociedad humana. Sin la persona, y sus derechos y sus deberes, la sociedad humana es invivible. Pero aquel derecho que es condición del ejercicio actual o potencial de cualquier otro derecho, es el derecho a la vida, o lo que es lo mismo, el primer deber de quien quiere cumplir sus deberes hacia otro, hacia mí en concreto, es el de no dañar, perjudicar o menos aún quitarle la vida.

En el "Decálogo", que en realidad es en medida importante un código social, un código destinado a manejar la vida social de un pueblo, el primer mandamiento de la 
segunda tabla del "Decálogo" es justamente "No matarás". Pero hoy día nos encontramos con que ese primer deber es cuestionado. Es cuestionado al proponerse la legitimidad del suicidio $y$, por ende, de la asistencia al suicidio, por lo menos al del enfermo terminal. Y luego, y esto se ha visto en todos los países donde esto se ha aceptado, al del que ya no es tan terminal, incluso aquel que encuentra simplemente que su vida ya no vale la pena. Se empieza por decir que se quiere aliviar los dolores de una persona que está sufriendo muchísimo, luego se pasa al que está sufriendo un poco menos; finalmente, a quien no quiere aceptar la situación que está ya sea física o moral. Esta es una cuestión de gran actualidad, las revistas médicas del mundo están llenas en este momento de artículos sobre este tipo de problemas. Es una cuestión de gran actualidad en algunos paises, y a propósito de esta cuestión, es siempre bien penoso opinar. Uds. comprenden que es tan doloroso el caso de una persona que ya no quiere vivir, que prefiere la nada, que se hace muy difícil formular un juicio sobre ese acto, máxime si como en este caso ha de ser necesariamente un juicio reprobatorio. Pero si se quiere ser consecuente, y aún manteniendo el máximo de respeto por el dolor, incluso la desesperación ajena, habrá que convenir que quien se mata asimismo no promueve la vida ni la protege y, además, en que escoger la nada, el aniquilamiento es la más irracional de las elecciones; es negar o desconocer cualquier valor apetecible en cualquier cosa.

El deber de promover la vida es aún más gravemente cuestionado en la eutanasia. Más gravemente digo, porque en ella alguien asume una representación de la sociedad para determinar que una persona no tiene la valía social que justifique mantenerla en vida. Puede tratarse de un enfermo inconsciente o de un recién nacido con malformaciones graves, o simplemente de un niño no deseado. Es curioso lo que pasa hoy día, porque la eutanasia fue un verdadero baldón. Recuerdo los días de mi juventud, una vergüenza para la Alemania de Hitler con su eliminación por decenas y decenas de miles de los recién nacidos enfermos. $Y$ ha pasado ahora a ser en muchas partes una acción justificada, y justificada por personas que pensarían que se las insulta groseramente si se las recuerda junto a los verdugos del nazismo, a los cuales, sin embargo, ellas imitan fielmente. $Y$ se dan hasta importantes entendidos en bioética, ciertamente que en una singular bioética, como profesores universitarios de la materia, como Peter Singer, que discurren que un ser humano recién nacido y enfermo puede tener un valor menor que un animal sano. Singer que es un hombre quizás brusco para decir las cosas, dice que entre un recién nacido enfermo y un chanchito sano, se queda con el chanchito. Me parece obvio que ninguna de las razones que se invocan para asesinar inocentes defectuosos tiene un auténtico valor. Mi deber de promover la vida se extiende a la de todos los seres humanos, y yo no podría conceder el derecho de calificar la valía de esa vida, sin abrir la posibilidad de que cualquier vida puede ser evaluada, incluso por supuesto la mía. Un deber de esta naturaleza o es universal o no existe.

El deber de promover la vida es cuestionado además del suicidio asistido y la eutanasia, en el aborto. La difusión del aborto en la última generación en el mundo occidental, no está tan ligada a los estudios científicos o filosóficos sobre el embrión humano, cuanto al florecimiento de ideologías sobre los llamados derechos reproductivos de la mujer. La facultad de abortar ha sido reclamada por muchos movimientos extremos como un derecho incuestionable. Así, por ejemplo, se argumenta que la penalización del aborto implica forzar a toda mujer a llevar su 
embarazo a término, aun cuando ella no lo desee. Ahora bien, la naturaleza discriminatoria contra la mujer que tiene esta obligación, se haría evidente desde el momento en que la mayor parte de las legislaciones conceden que hay ciertas condiciones bajo las cuales el aborto es admisible. Esto me parece muy importante recordar hoy día aquí en Chile, porque se empieza hablar del aborto en tales o cuales condiciones: el aborto cuando pone en riesgo la vida, el aborto cuando pone en riesgo la salud, el aborto cuando pone en riesgo la seguridad de la madre. Eso, esa disposición es radicalmente negada por los defensores consecuentes de una tesis abortista, porque esa posición involucra una calificación que hace la autoridad de lo que a la mujer debe importarle. En otras palabras, el derecho a la vida del niño que ha de nacer no sería ningún absoluto, y las limitaciones que se le imponen estarían revelando el sustrato ideológico de la legislación que la sustenta. Hay un estudio muy instructivo de Reva Siegel en que se presenta un análisis de la legislación en el Estado de Utah en los Estados Unidos, estudio que es ilustrativo sobre este punto de vista. La mencionada legislación, la de Utah, establece excepciones "cuando el aborto es necesario para salvar la vida de la mujer embarazada". El caso de que "la preñez sea resultado de la violación" o "resultado del incesto" o también "para impedir el nacimiento de una criatura que sería portadora de graves defectos". El Estado, comenta Siegel, partidaria declarada y radical del aborto, no actúa entonces en forma consistente para proteger la vida del niño que ha de nacer, desde el momento en que se halla de acuerdo en subordinar el bienestar del fruto de la concepción al bienestar de la mujer, pero principalmente en aquellos casos en los que ésta sufrirá graves daños físico por el embarazo. De esta manera, dice Siegel, el Estado de Utah limitaría su interés de la libertad de la mujer al interés en su mera supervivencia física, como si las mujeres carecieran de identidad social, intelectual o emocional que trascendiera su capacidad fisiológica de portar criaturas en su seno. Análoga crítica le merecen a Siegel las disposiciones que permiten el aborto luego de violación o de incesto. Entonces si se admite que existen algunas condiciones bajo las cuales el aborto sería aceptable, sería, para la autora, inevitable la conclusión de que cualquier conjunto de reglas de admisibilidad reflejaría un juicio sobre la importancia relativa de las actividades de la mujer, y una restricción de sus derechos, la que obviamente no es aplicable al varón, y expresaría por lo tanto una discriminación ilegítima. Así la misma Siegel, refiriéndose con idéntico criterio a otro caso legal práctico, hace ver que no sería en Estados Unidos constitucionalmente lícito, es una opinión, no hay decisión de la Corte, no sería constitucionalmente lícito impedir a la mujeres en edad fértil el trabajo en condiciones en que arriesgan la salud del feto por emanaciones de plomo. Esta es una condición bastante frecuente, por ejemplo, en trabajos de imprenta. Hay una gran cantidad de trabajos industriales en los que la persona está sometida a emanaciones de plomo que causan algunos daños en la salud, y que son bastante dañosas en el caso del embarazo. En el caso de estar sometida a esas condiciones, para Siegel, la interesada debería tener siempre abierto naturalmente el recurso al aborto. De hecho, lo que la legislación hace al recurrir a esta prohibición aparentemente benévola, dice Siegel, es preferir la condición natural de la maternidad a la libertad de trabajo y de aprovechamiento de oportunidad de progreso individual de la mujer. Estas cuestiones nos ponen cerca de la verdadera dimensión social del problema, la que ha sido caracterizada por Kristine Luker, también connotada exponente de la posturas abortistas, diciendo, "el debate sobre el aborto tan apasionado y duro, porque es un referendum sobre el sitio y significado social de la maternidad". Nótese que no habla de un referendum sobre la 
condición o el estatus del embrión o feto, sino sobre las condiciones o estado de la mujer.

La reciente polémica sobre el veto del Presidente Clinton a la ley que prohibía dar muerte a un niño en las últimas semanas de la gestación, es tristemente ilustrativa. Nadie que haya visto, muchos de Uds. pueden haberlo visto en su propia familia, a un recién nacido prematuro de siete meses y medio, ocho meses de embarazo, tiene derecho a olvidar que ese niño es en todo comparable a un feto que tenga su misma edad de gestación. Por lo general pensaríamos, y el Presidente Clinton el primero, que matar al prematuro es un crimen, entonces ¿cómo puede encontrarse admisible que se mate al feto que es igual a él? . La única respuesta es que se estima en mayor valor la facultad de la madre para matar que el derecho de esa persona a vivir, y que, por lo tanto, para los que así creen, no existe siempre el deber de respetar, acoger y promover la vida de un ser humano inocente. En el fondo los derechos de la persona quedan subordinados al consenso social.

Aquí se percibe la dimensión social del conflicto, el cual no radica en la determinación biológica o filosófica del estatus del embrión o feto, sino en el derecho de la mujer a no verse privada por el hecho de ser tal, a ninguna de las presuntas ventajas del otro sexo. Eso es a mi entender lo que quiere decir Kristine Luker, y ello coloca la polémica sobre el aborto dentro del grupo de los grandes conflictos sociales.

Vale la pena, aunque sea como un paréntesis, preguntarse de donde saca su fuerza esa postura. Yo respondería que al menos una parte de ella proviene de que esa postura se coloca en la línea de una interpretación de la sociedad, que hace radicar la estructura básica de la historia y su dinámica de progrešo en el conflicto. Siegel, la misma autora, comentando el libro de Kristine Luker "Abortion and the politics of motherhood", "El aborto y las políticas de la maternidad', dice que ella demuestra que los conflictos sobre el aborto, estoy citando, reflejan puntos de vista divergentes sobre el verdadero rol de la sexualidad, el trabajo y los compromisos familiares, y que en ellos se oponen aquellos que ven a la maternidad como el rol más importante y más satisfactorio que se le abre a una mujer, y aquellos para quienes la maternidad es uno de los roles posibles, pero que es una carga cuando es definido como el único. Se cree renocer aquí el eco de las palabras de León Trotsky cuando en su libro "La Revolución Traicionada" y refiriéndose a los primeros tiempos de la revolución de Lenin, habla, lo cito; "del antiguo hogar familiar, institución arcaica en que la mujer del pueblo languidecía condenada a trabajos forzados de la infancia a perpetuidad", a lo cual agregaba "es justamente por eso que el poder revolucionario ha concedido a la mujer el derecho al aborto como uno de sus derechos esenciales", en lo cual digo yo, no hacía, sino aplicar las palabras tan conocidas de Engels, el ilustre colaborador de Carl Marx cuando dice "el primer antagonismo de clases que apareció en la historia, coincide con la aparición del antagonismo entre el hombre y la mujer, y la monogamia y la primera opresión de clases con la del sexo, el femenino por el masculino."

El planteamiento que he esbozado de Siegel tiene la virtud de que pone las cosas en su verdadera perspectiva. No le da mayor importancia al aborto terapéutico por indicaciones médicas y tampoco hace mayor cuestión de que el feto sea o no un ser humano. Nadie podría razonablemente poner en duda que un feto de 8 meses de gestación es un ser humano. Simplemente declara que más importante que mi deber de respetar esa vida, es mi facultad de hacer lo que yo quiera en la prosecusión de mis 
fines. Es claro que se le concede aquí a la facultad de decidir, un valor abrumadoramente mayor que al deber de respetar al otro.

En los tres casos analizados, el deber de respetar la vida de la persona se halla supeditado a otras consideraciones. En el caso de la eutanasia a la conveniencia social. En el caso del suicidio o del aborto, a una especial concepción de la libertad a la que me referiré brevemente más adelante.

Pero hay un problema que ha recibido un tratamiento algo distinto y es el de los abortos muy precoces, los microabortos, y la experimentación en los embriones humanos precoces, porque allí lo que se nos dice es que no estamos tratando con seres humanos, con personas, sino con tejidos humanos, algo así como con órganos o estructuras que no tienen existencia personal y, que, por lo tanto, no son acreedores al respeto de que he estado hablando. El problema es complicado, porque naturalmente un embrión precoz, de pocos días o semanas de gestación, ni habla, ni siente, ni se relaciona de ninguna de las manera que asociamos a los mecanismos de relación de una persona. Por otro lado, parece evidente que la persona como tal tiene que tener su origen o inicio en algún punto tiempo que es anterior al de su plena madurez. Por primera vez en su historia se plantea hoy la cuestión que si un organismo humano, como lo es evidentemente el embrión, puede no ser una persona. Estrictamente hablando esto no es un problema de la ciencias biológicas, porque no existe criterio biológico para calificar a alguien de persona, pero dado el peso que tienen las ciencias hoy día, vale la pena detenerse sobre los aportes que ellas pueden hacerle a la cuestión.

Vale la pena una disgresión, aunque sea un poquito larga, en este punto, porque ella nos dará una perspectiva interesante sobre un aspecto que es crucial en mi exposición y que es lo que es el respeto a la persona. Veamos un poco la biología del asunto. El año 1875 Hertwig descubrió el fenómeno de la fecundación. O sea que dos células, una proveniente del padre y la otra de la madre, se fusionan, por decirlo así, para producir una nueva célula: el huevo fecundado o cigoto, que empieza de inmediato a comportarse como un pequeño organismo. Antes de esa fecha, antes del descubrimiento de Hertwig, las ideas sobre generación de la vida eran muy variadas y muy confusas. Una idea muy en boga era que a partir, ya fuera del líquido seminal, ya del líquido menstrual se armaba por coagulación un ente, al que posteriormente el calor animal le confería la vida. Era gente que estaba haciendo una deducción a partir de la gallina que empolla sus huevos; ellos veían huevos en que no se veía ninguna forma visible y la gallina se ponía encima, lo calentaba y salía un pollito. Era un poco las líneas de raciocinio ingenuo, pero bastante elaborado de esa gente. Esta era una hipótesis manejada en el Siglo XVIII, y que era una elaboración de ideas de Aristóteles y de Santo Tomás de Aquino, para quienes, ignorantes del cómo del proceso, no había una mayor dificultad en suponer una especie de animación progresiva. Una masa más o menos desorganizada iba adquiriendo poco a poco una forma humana o animal, según el caso. Geoggroy Saint-Hilaire, uno de los grandes naturalista franceses de fines del Siglo XVIII hablaba como de un ensamble de los materiales, como si el ensamble de los materiales fuera anterior a la vida del individuo, pero con el descubrimiento de la fecundación todo cambió. Ahora se encontraba la ciencia con un momento definido en que se constituía un pequeño organismo con todas las características biológicas de tal, y en cuya formación han tomado parte elementos de ambos progenitores, y así comenzaba un desarrollo independiente. A los pocos días el embrión se anida en el útero y a las pocas semanas su forma humana, su forma visible humana, es claramente 
identificable para cualquier observador. Esa forma continuaba perfeccionándose hasta el término del embarazo. El proceso tiene por supuesto etapas, pero no tiene ni interrupciones ni discontinuidades. Así el nuevo organismo empieza a producir materiales propios de él y que son necesarios para su desarrollo, y empieza a regular su relación con su medio, con el interior de las Trompas de Falopio o del útero. Estos materiales que fabrica el pequeño organismo son además nuevos y distintos a los que fabricaba el óvulo antes de la fecundación, y lo son al menos desde el momento siguiente a la primera división celular, o sea para tomar las cosas bien, pienso de seguro, a las 24 horas de producida la fecundación ya el embrión está produciendo cosas propias para funcionar en el proceso al que le hace frente, que es el de llegar a anidar en el útero. Se empieza a expresar un nuevo genoma o sea una combinación de genes, distintas a la del padre y la de la madre, porque es una combinación de ambas. Muy poco más adelante el pequeño organismo está produciendo, como decía, materiales que le van a ser útiles para anidar, para instalarse en el útero, pero al mismo tiempo muestra desde muy al comienzo una sorprendente capacidad de regular su propio desarrollo, lo que se llama en fisiología la osmostiasis, que es una característica fundamental de la vida de cada uno de nosotros que regulamos nuestros procesos vitales. El embrión desarrolla una capacidad realmente sorprendente de osmostiasis, ordenando la diferenciación de sus células incluso frente a importantes agresiones experimentales, como lo demostró hace ya más de 20 años la escuela de Minst, uno puede reemplazar una célula del embrión por una célula de cancer embrionario de otro animal, y esa célula de cáncer embrionario es obligada a desarrollarse como célula normal del embrión, y se integra al embrión o sea llega a formar parte del mismo todo, un poco como si se le hiciera un injerto. La anidación en el útero, que es uno de los instantes fundamentales en este proceso, es el resultado de procesos bioquímicos coordinados del embrión y el útero materno. Inmediatamente antes de anidar, al romperse la llamada membrana vitelina que envuelve al embrión, se produce el fenómeno llamado de "Hatching". "Hatching" es la palabra inglesa con que se designa la rotura del cascarón por un pollito, y en ese momento el pequeño embrión que sale de la envoltura vitelina es capaz, al igual que muchos otros organismos, algunos vermes, algunos gusanos, de reproducción asexuada, dando origen a los gemelos univitelinos o iguales. Sale el embrión y en la salida un poco como que se estrangula y se parte en dos, y en vez de un animalito por decirlo así, hay dos. Un poco lo mismo que pasa cuando uno toma uno de estos gusanos de agua dulce o una planaria y lo parte en dos con una navaja y a los dos días tiene dos gusanos. El pequeño organismo, este embrión, es indudablemente un organismo, por lo tanto, y además, es también un organismo humano, eso no lo puede discutir nadie, pero además es un organismo básicamente distinto del de sus progenitores, porque tiene una combinación de genes que es diferente. Sin embargo, se nos dice que no tiene conciencia, porque no tiene sistema nervioso todavía, entonces no es una persona. No hay duda, sin embargo, que con solo darle el tiempo, sí que va a mostrar un sistema nervioso que ya estaba desarrollando desde el comienzo, porque si yo quiero observar todas las manifestaciones personales de un organismo es sólo cuestión de esperar. Análogamente a como es cuestión de esperar unos meses para oír hablar a un recién nacido. Me dirán que hay algunas etapas precoces en las que yo no puedo probar que se trata de una persona, pero nadie podrá negar que tengo buenas razones para pensar que pudiera hacerlo y que los argumentos en contra no son en absoluto convincentes. Entonces, al menos, nos encontramos en una situación de incertidumbre. ¿Se trata o 
no de un ser humano?. Ahora aquí está el punto crucial, porque si yo creo que sí, yo pienso de verdad que le debo un especial respeto al ser humano, en la duda, estoy obligado a tratar a ese embrión que podría serlo como si lo fuera. A la inversa, si procedo como hoy día se hace, esto es acumulando embriones por millares para destruirlos o para experimentar con ellos y no puedo ciertamente tener la seguridad de que no son seres humanos lo que estoy diciendo con mis actos, con mi actitud, no con mis palabras, es sencillamente que el deber de promover la vida humana no me parece ni tan importante ni tan fundamental.

De este modo suicidio, aborto, experimentación embrionaria, eutanasia, son síntomas de una actitud de menosprecio frente a eso que nos parecía un deber fundamental, cual es el de respetar, acoger y promover la vida de todo hombre.

¿Ahora por qué insistir tanto sobre éstos y no sobre otros atentados?.

Voy a tratar de desarrollar una hipótesis que me parece a mí al menos plausible. No debería extrañarnos demasiado que hubiera este menosprecio práctico por el ser humano, porque sería muy ingenuo olvidarnos del atroz balance de este siglo en cuanto al respeto por el hombre: dos Guerras Mundiales, revoluciones espantosamente crueles en el mundo, guerras civiles y tribales, hambrunas provocadas, han cobrado literalmente miles de millones de vidas de personas asesinadas a menudo con la más refinada crueldad. Pero además han tenido lugar genocidios, en los cuales el otro hombre es tratado como enemigo no por lo que me haya hecho, sino por lo que él es, y que se han registrado en muchas partes, en Europa, en Africa, en Asia, y cuyo paradigma infame es por supuesto el Holocausto, más aún, la trágica historia de explotación de los seres humanos, el trato reservado a niñas y mujeres, la suerte de las colonias de las grandes potencias, la de los pobres y los débiles, las persecuciones, el terror y la tortura erigidos en sistemas, la profanación y degradación del medio ambiente humano, la misma perduración de la pena de muerte, todo eso, mirado en conjunto, muestra una vida social marcada por el signo de la muerte. Agreguemos que el hecho a que en el mundo se lleven a cabo anualmente más de cincuenta millones de abortos, o sea que más de cincuenta millones de seres humanos fueron odiados o despreciados por sus propias madres, hasta ser eliminados, todo eso llega a ser escalofriante.

Y no es sólo cosa de pobreza o ignorancia, aunque si así fuera, ya sería bastante para llamar a juicio a una civilización que tiene tanto y lo distribuye tan mal, pero no es cosa de pobreza. En los Estados Unidos, país rico, casi un $30 \%$ de los embarazos terminan en aborto; por cada dos niños que nacen debería nacer por lo menos uno más. Y lo mismo ocurre en países europeos, a pesar de que afrontan una dificilísima crisis por el déficit de natalidad. Acuérdense solamente de ésto, la cifra de reposición de la población de un país es del orden 2,2 hijos por pareja, o sea si en promedio la población tiene 2,2 hijos por pareja se mantiene estable la población del país. Hay países europeos que encaran cifras estremecedoras del orden de 1,5 hijos por pareja, lo que amenaza a esos países de extinción en un plazo definido, o a no ser que recurran como lo han hecho en el pasado a la importación masiva de mano de obra barata y prolífica, que naturalmente les acarrea problemas sociales imposibles de manejar. $Y$ a esos niños, a esos mismo niños que tanto necesitan, los matan antes de que nazcan con ayuda de los servicios estatales de salud. 
Me acuerdo de un caso bastante espectacular, una niña norteamericana a quien yo conocí y que sobrevivió al aborto que mató a su hermano gemelo; era un embarazo gemelar. Hicieron un aborto y el médico se equivocó y sacó a una guagua no más, no supo que había dos, y cuando unas semanas después la madre estaba leyendo, se sentía mal y había quedado muy traumada. - las mujeres que se provocan abortos a menudo quedan muy traumadas por el sindroma post aborto -, estaba leyendo sentada, cuando de repente sintió una patada en su vientre y se dio cuenta que tenía una guagua viva, que naturalmente el facultativo que la había atendido le ofreció sacársela y ella dijo que por ningún motivo. Que ese crimen lo hacía una vez. Y la niña sobrevivió, es una niña muy encantadora, y tal vez pensando en los millones de vidas de sus compatriotas que fueron segadas en el mismo año de su nacimiento en su país ella nos decía: "Mire, estoy ante Uds. como un sobreviviente de Auschwitz, del campo de concentración de Auschwitz", y ese Auschwitz no se había generado por supuesto ni por pobreza ni por ignorancia.

Justamente la lección que nos dejan el aborto, la eutanasia y el suicidio asistido, la lección que nos dejan y que hace que valga la pena ocuparse de ellos a pesar que hay tantas otras formas de atentar contra la vida, una lección que nos dejan repito, es ésta. Si nos hablan de guerras tribales, de las guerras en Biafra, o en Somalía, o que se yo donde, que matan decenas de millones de personas y nos hablan de matanzas, de persecuciones, siempre tenemos la tendencia de pensar, o a decir, que esas son cosas que hacen otros, tal vez gente mala, tal vez gente enferma, verdaderos accidentes en la historia de la humanidad. Pero verdaderamente estos hechos a los que me he referido son llevados a cabo muchas veces por gente buena, respetable, seria, madres y padres de familia, médicos, enfermeras y científicos. No son fruto de la pasión que ciega sino del cálculo incluso bien intencionados. Por allí dicen que el infierno está empedrado de buenas intenciones. Dejan entonces una terrible lección, todos, todos nosotros podríamos llegar a hacer lo mismo.

El argumento que se esgrime más frecuentemente es el de la libertad, es el que esgrimen las personas bien digamos, ya se trate de la libertad de la mujer, de libertad para quitarse la vida, o de libertad para escoger algún punto de referencia más valioso que el de la mera persona, por ejemplo, en la eutanasia, y al hablar de libertad tocamos el núcleo de la existencia humana. Pensemos para terminar, nadie dice, ninguno de nosotros diría que tiene libertad para robar, estafar, engañar o traicionar. Por qué se dice entonces que haya de haber libertad para matar. Así advertimos que hay un abuso en los términos. Yo tengo la facultad de hacer esto o aquello, pero eso es distinto de lo que llamo propiamente la libertad que es justamente la facultad de adherir por propia decisión a lo que es bueno, hermoso y deseable, no a lo malo, no a la aniquilación, no a la muerte. No se puede hablar sin un abuso en los términos de libertad para cometer delitos. Así cuando frente al aborto se plantea la alternativa "pro choice" o "pro life" la alternativa norteamericana por la libre elección o por la vida, se está incurriendo en una falacia, se contrapone una facultad, la facultad de escoger que tiene un orden de medio o instrumento enfrentándola o comparándola a algo que es un bien, el fundamento o condición de todos los bienes de los hombres que es la vida.

Bien, adverso como soy a toda clase de aborto podría decir que soy "pro choice", estoy por un recto uso de de la facultad de escoger y dada la naturaleza del bien la vida, el recto uso de la facultad hace que escoja la vida. 
Me acuerdo de una anécdota que viene tal vez al caso, que no tiene más que un mérito, que es verdad. Se trataba de una mujer, una señora en Europa, madre de familia, con niños ya de quince años, que se embaraza, y tienen una especie de consejo de familia y deciden que, bueno, que las piezas de la casa ya son insuficientes, la renta, cualquier cosa, que lo que hay que hacer es abortar. La señora no estaba muy convencida pero incluso sus hijos la convencían, y su marido, de que era lógico. Entonces, bueno, se va al hospital, y va a hacer los trámites, y se recuerda que tiene que hacer una llamada por teléfono, no hay un teléfono a mano por ahí, y sale a un teléfono público que está en la calle, entra a la caseta y se encuentra allí con algún papelito de estos que dejan a veces los predicadores ambulantes, de estas cosas, con citas bíblicas que había quedado allí, está marcando un número y dice: "He aquí que pongo delante de tí (palabras del Deuteronomio) dos caminos: el del bien y el del mal, el de la vida y el de la muerte. Escoge la vida". La mujer se fue a su casa y no se hizo el aborto, a pesar de todo el tremendo problema familiar, el punto fue que ella entendió que ella tenía que escoger, pero tenía que escoger lo bueno, porque si no, no hay derecho a escoger.

Para nosotros los cristianos es fundamental el modo como la revelación guardada y enseñada por el magisterio de la iglesia, va reafirmando y confirmando los datos que aporta la razón natural y los abre luego a insospechadas perspectivas. Todo lo que yo he dicho hasta aquí, lo podría haber dicho prácticamente sin aludir para nada al magisterio de su enseñanza. Esto me parece que es lo que desprende de una sana consideración del ser humano, pero si veo el magisterio veo que esa sana consideración del ser humano recibe una confirmación y una proyección nueva que son insospechadas.

Eso es lo que ocurre, por ejemplo, con la encíclica "Evangelium Vitae". Esa Encíclica reivindica lo venerable de la vida humana, nos dice que ella es siempre un bien y nos muestra que esa realidad, que ya podíamos percibir sin ayuda de la fe, está cimentada sobre tres elementos: la vida humana es una realidad, no el resultado de algún punto de vista de un observador o de una concesión de algún grupo social; segundo, ella es una realidad sagrada, fundante, porque fue asumida por el Verbo de Dios en la encarnación y; tercero, ella no es una realidad última, sino penúltima, porque es expresión de nuestro ser de criaturas, amadas de Dios. Por eso, lo que la Encíclica llama el "núcleo del evangelio de la vida" es el anuncio de un Dios vivo y cercano, la afirmación del núcleo indivisible de la persona humana a la cual Dios se le acerca y al cual dignifica. La Encíclica se extiende, por supuesto, sobre esta forma socialmente aceptada en muchas partes de matar, mostrándonos cuan grave es el daño que su aceptación produce en las legislaciones y en la convivencia social. Su consideración detallada nos da criterios para enfocar el conjunto de los otros atentados contra la vida, pero al mismo tiempo la Encíclica refuerza nuestra esperanza al mostrar el inmenso desarrollo que el servicio a la persona humana ha tenido en este siglo.

La codificación y defensa cuando son bien intencionadas de los derechos humanos; el desarrollo de la medicina y de la atención médica, especialmente para la vida naciente; las innumerables iniciativas de protección y defensa de los débiles y de los enfermos; la acogida de los niños sin hogar; la defensa de los derechos del niño y de los derechos y posición social de la mujer; la sensibilidad anti - guerra; las innumerables familias que toman a lo serio su rol de formadoras de las personas; el heroico sacrificio de médicos y personal sanitario que hacen objeción de conciencia a las prácticas 
nefandas del aborto y la eutanasia, y sacrifican con ello su promoción y su carrera; el cuidado de los moribundos y abandonados en hospitales, en asilos, y hasta en las calles de grandes ciudades. Mil formas por las que se manifiesta que son muchos, que cada vez son más, los que entienden lo que es cada persona, aquellos a quienes la Encíclica llama "el pueblo de la vida".

Yo entiendo que hay un problema, para muchas gentes, cuando ve la inmensa fuerza que adoptan formas de poder, de esta ofensiva descarada abierta contra la vida en tantos planos, y que se sienten inermes y pequeñas. Les recuerdo que la difusión del Evangelio en el mundo occidental ha seguido justamente esa ley. En el Siglo V o en el Siglo VI. el poder parecía estar destinado para siempre a manos de los que eran los poderosos de su tiempo, individuos que ya sean en el Imperio o entre los pueblos bárbaros, eran sedientos de poder, de lujuria, de riquezas, violentos. ¿Cuál fue la respuesta cristiana a ellos?. Fue una respuesta muy paradójica, muy extraña. Fueron los monasterios de la Edad Media en que pequeños grupos de ocho, diez, doce hombres se juntaban a alabar a Dios, sin ningún poder, ninguna fuerza, sin ninguna violencia, desde luego. Pero el espíritu tiene una fuerza tan contagiosa que fueron esos pequeños monasterios, y no los representantes de un imperio decadente, los que hicieron Europa e hicieron toda la grandeza y la belleza de la civilización occidental.

Así a veces yo pienso que dentro de este mundo agitado y complejo en que nos toca vivir, esa cosa humilde, buena, atrayente, que es una familia noblemente inspirada, una familia en que se cultiva y se exalta el valor de las personas y su dependencia de Dios, es esa familia la que tiene la llave del porvenir. 